Article

\title{
An Elastic Charging Service Fee-Based Load Guiding Strategy for Fast Charging Stations
}

\author{
Shu Su, Hang Zhao, Hongzhi Zhang * and Xiangning Lin \\ State Key Laboratory of Advanced Electromagnetic Engineering and Technology, \\ Huazhong University of Science and Technology, Wuhan 430074, China; sushu@aliyun.com (S.S.); \\ zhaohangtc@hotmail.com (H.Z.); linxiangning@hotmail.com (X.L.) \\ * Correspondence: hongzhi_zhang@hust.edu.cn; Tel.: +86-27-8754-3437
}

Academic Editor: Issouf Fofana

Received: 18 March 2017; Accepted: 2 May 2017; Published: 11 May 2017

\begin{abstract}
Compared with the traditional slow charging loads, random integration of large scale fast charging loads will exert more serious impacts on the security of power network operation. Besides, to maximize social benefits, effective scheduling strategies guiding fast charging behaviors should be formulated rather than simply increasing infrastructure construction investments on the power grid. This paper first analyzes the charging users' various responses to an elastic charging service fee, and introduces the index of charging balance degree to a target region by considering the influence of fast charging loads on the power grid. Then, a multi-objective optimization model of the fast charging service fee is constructed, whose service fee can be further optimized by employing a fuzzy programming method. Therefore, both users' satisfaction degree and the equilibrium of charging loads can be maintained simultaneously by reasonably guiding electric vehicles (EVs) to different fast charging stations. The simulation results demonstrate the effectiveness of the proposed dynamic charging service pricing and the corresponding fast charging load guidance strategy.
\end{abstract}

Keywords: electric vehicles; fast charging; real-time pricing; charging station selection; navigation strategy

\section{Introduction}

With the adjustment of global energy strategies, the energy transition and comprehensive social benefits generated by the electric vehicle (EV) industry has attracted significant attention. As the penetration rate of EVs has gradually increased, the traditional time-oriented slow-charging mode can hardly meet the urgent and efficient charging demands for a myriad of EVs within a short time. Fast charging, a novel technology to replenish EVs in the short-run, is the future development orientation. However, the access to large-scale, disordered and random fast-charging loads will generate uncertainties in both time and space dimensions, which will exert unpredictable negative effects on the safe and stable operation of the grid [1-7]. Thus, EVs' fast charging behaviors should be orderly coordinated.

EV users' charging charge location selection and path planning behaviors are mainly affected by four factors: the geographic location of charging stations, charging service fees, user types and their travel characteristics. Recent years have witnessed a lot of studies conducted by scholars concerning price-guided orderly charging strategies. In [8], an optimization model where the objective was to minimize the peak-valley slip ratio, and formulate peak-valley time-of-use pricing was put forward to achieve peak-load shifting. In [9], a multi-objective control method was proposed, which was based on time-of-use (TOU) pricing and regarded the minimal charging fees and the earliest initial charging time as the objective of two-stage control, and the effect of "peak-load shifting" and users' economical charging were achieved. In [10], a coordinated charging control method for EV charging stations was 
put forward based on dynamic TOU prices, which reduced the operational cost and achieved the desired "peak-load shifting" effect.

The above studies have effectively achieved coordinated charging "peak-load shifting" effects toward the gird by regulating EV's initial charging time through "TOU prices" and "peak-valley prices" and have demonstrated the feasibility of guidance of charging behaviors by modulating charging service fees. However, the price above was still fixed and cannot be changed in real-time. In the future, the construction of charging stations will open the gate for the entry of social capital. Under such circumstances, power grids and charging stations will have the decision-making ability of allowing their charging service fees to fluctuate within a reasonable range. On the other hand, the current research focuses mainly on the slow charging users, without considering their fast charging demands dispatching power randomly along the road. Secondly, the guidance of charging service fees focuses primarily on regulating charging time, neglecting its effect on the space dimension, which leads to the imbalanced distribution of charging loads. Moreover, current research on the guidance effects of charging service fees based on "peak-valley price" only considers the perspective of the safe operation of grid, while neglecting different types of users' response to the charging fees. The calculation of users' own benefits also needs to be improved.

On the other hand, there are several studies in the field of charging behavior guidance and charging station operation. In [11], an optimal EV charging scheduling problem for a load aggregator (LA) was developed on the consideration of its revenue and EV owner's demands and costs. The paper proposed an adaptive charging rate for each vehicle in order to support gird stability. In [12], a scheduling model for EV charging stations was proposed to minimize the total charging costs and energy costs from the substation. In [13], a novel load management solution for coordinating the charging of multiple plug-in electric vehicles (PEVs) in a smart grid system was proposed. The approach enables EVs to begin charging as soon as possible considering priority-charging time zones while complying with network operation criteria. In [14], a real-time price based automatic demand response strategy for EV charging stations was proposed, which aims at reducing electricity costs, and mitigating peak charging demand.

In this paper, we first analyze the responses of different types of users toward the selection of charging location and charging service fee, and then we construct a multi-objective decision model based on the optimization goal of achieving both a degree of regional charging balance and user satisfaction. An intelligent algorithm is utilized to calculate the charging service fee at each fast charging station (FCS) in the target region. Finally, we verify the guidance effects of charging service fee and charging loads by using integrated simulation system of IEEE 33-node distribution network and its corresponding road network. The results demonstrate that, by regulating the charging service fees of different FCSs while ensuring the user satisfaction, EVs can be reasonably coordinated at every FCS, thus the charging loads are evenly distributed in the area.

\section{Analysis of Charging Location Selection and Charging Service Fee Response Based on User Classification}

\subsection{Standard Classification of EV Fast Charging Users' Charging Location}

The initial charging time and the selection of charging location vary with different EV users. The initial time of fast charging cannot be arbitrarily changed due to the urgent need and rigid demands of charging time. Therefore, this section will mainly focus on the charging location selection criteria.

At present, research on intelligent transport systems (ITSs) has developed dramatically [15], and is able to estimate the time to reach a target location by considering the traffic flow. In the future, with its integration with the intelligent charging navigation system, by using an ITS, every travelling EV user can not only estimate in real-time the time needed to reach FCSs, but also get access to the occupancy rate at each FCS based on the current dynamic traffic flow.

Based on such a tendency, it is assumed that all users are rational and there can be differences among the charging service fees for each FCS. An EV user's choice of FCS can be generally divided 
into three categories under the condition that the remaining state of charge (SOC) is enough to reach his or her destination:

- Class I: In the absence of an ITS, users will choose the nearest FCS;

- Class II: With access to an ITS, cost-insensitive users' general choice will be the FCS where they can finish the charging process in the shortest time;

- Class III: With access to an ITS, cost-sensitive users will generally consider both the charging time and charging cost. When the charging time is within the affordable range, their priority will be the one where the charging cost is relatively low.

When the charging demand is generated, the total charging time can be expressed using Equation (1):

$$
T_{\mathrm{d}}=T_{\mathrm{a}}+T_{\mathrm{q}}+T_{\mathrm{c}}
$$

where $T_{\mathrm{d}}$ is the total charging time (hours); $T_{\mathrm{a}}$ is the arrival time (hours), namely the time needed to travel to the FCS; $T_{\mathrm{q}}$ is the queuing time (hours), and the detailed deduction is given in the Appendix A; $T_{\mathrm{C}}$ is the charging time (hours) — the time from the start of charging to the end of charging.

The overall charging cost is shown in Equation (2):

$$
C_{\mathrm{d}}=C_{\mathrm{a}}+C_{\mathrm{s}}=C_{\mathrm{t}}+C_{\mathrm{c}}+C_{\mathrm{s}}
$$

where $C_{\mathrm{d}}$ is the total charging cost (China Yuan, $\mathrm{CNY}$ ); $C_{\mathrm{a}}$ is the arrival charging cost (CNY), that is, the charging cost when the vehicle reaches a charging station considering the electricity consumption during the driving process. $C_{\mathrm{s}}$ is the cost of the charging service fee $(\mathrm{CNY}) ; C_{\mathrm{t}}$ is the cost of travel (CNY), which is the charging cost of the amount of electricity consumed by the vehicle in the process of traveling to the corresponding fast charge station; $C_{c}$ is the charging cost $(\mathrm{CNY})$ in the charging station.

According to the above user classification, the selection of charging location for Class I users and Class II users depends on the location of the vehicle, the road traffic condition and the charging waiting time. It is difficult to alter the charging behaviors of these two types of users by merely adjusting the charging service fee. The Class III users are sensitive to the price, so their charging behaviors can be guided by setting different charging prices or charging different service fees for different FCSs.

Since the grid behavior can affect the profit of charging stations by adjusting the charging fees and returning a rebate to charging stations, therefore, from the perspective of the charging stations, it's beneficial to participate in the charging fee adjustment strategies. Also, the power flow of the grid, transmission losses, power quality and other indexes can be optimized in this process, so this strategy is a win-win situation, and it's reasonable to assume that all the charging stations will participate in this regulation.

\subsection{User Charging Location Selection Probability Based on a MNL Model}

Firstly, the user proportion adopting different charging location selection strategies has to be determined, i.e., we need to determine the probability of each strategy that EV users will employ in selecting a charging location as mentioned in Section 2.1. Since nowadays the EV penetration rate is relative low, ITS is in a theoretical stage, and the relevant statistical data is insufficient, so this paper adopts the multinomial logit model (MNL) [16], and obtains an actual distribution of the various types of users through questionnaires, thus determining the users' selection probability.

The MNL is a probabilistic selection model that has been widely used in traffic demand side management strategies [16,17], and it is particularly suitable for predicting user's travel behavior. Naturally, this model can also be employed for the prediction of decision-making processes concerning the selection of charging locations.

According to the MNL, let $P_{i}$ be the probability for $i$-th selection criteria of a charging location. For the Class I, II and III charging location selection criteria described in Section 2.1, the probability 
are $P_{I}, P_{I I}$ and $P_{I I I}$ respectively, where the $P_{\mathrm{I}}$ can be obtained directly by calculating the probability of installing ITS. If Class III is viewed as a reference, $P_{I I}$ can be described according to a logistic formula:

$$
\ln \left(\frac{P_{i}}{P_{I I I}}\right)=\alpha^{i}+\sum_{k=1}^{K} \beta_{k}^{i} x_{k}^{i} \quad(i=\mathrm{I}, I I)
$$

where $i$ is the selection criteria, except for Class II users; $\alpha_{i}$ is the constant term for $i$-th option; $x_{k}^{i}$ is $k$-th variable of $i$-th option is used; $\beta_{k}^{i}$ is the corresponding coefficient of $x_{k}^{i}$.

It can be derived from (3) that:

$$
\left\{\begin{array}{l}
p_{I}=1-p_{I T S} \\
p_{I I}=\frac{e^{\alpha^{2}+\sum_{k=1}^{K} \beta_{k}^{2} x_{k}^{2}}}{\alpha^{\alpha^{2}+\sum_{k=1}^{K} \beta_{k}^{2} x_{k}^{2}}} \cdot p_{I T S} \\
p_{I I I}=\frac{1+e^{1}}{1+e^{\alpha^{2}+\sum_{k=1}^{K} \beta_{k}^{2} x_{k}^{2}}} \cdot p_{I T S}
\end{array}\right.
$$

In order to obtain the probability of the users' adopting different types of criteria, the MNL model was calibrated by analyzing targeted statistical data, adopting data analysis software such as Statistical Product and Service Solutions (SPSS), and using a polynomial logistic regression to calculate constant $\alpha$ and the corresponding coefficient $\beta$ of the variables. However, due to the lack of relevant statistical data, it is necessary to collect samples. We set the personal attributes of EV users and the vehicle attributes as variables for charging location selection criteria, and we made a summary table as shown in Table 1. Through sufficient data collection and the regression analysis of the sample statistics to get MNL model parameters, if the owner' sex, age and vehicle type are known, the probability of adopting different selection criteria can be obtained.

\begin{tabular}{|c|c|c|c|c|c|c|}
\hline \multirow{2}{*}{\multicolumn{2}{|c|}{$\begin{array}{l}\text { EV Users' Personal Attributes } \\
\text { and Vehicle Types }\end{array}$}} & \multirow{2}{*}{$\begin{array}{c}\text { Is ITS } \\
\text { Installed? }\end{array}$} & \multicolumn{2}{|c|}{$\begin{array}{l}\text { Cost Per Unit Charge } \\
\text { (CNY/kWh) }\end{array}$} & \multicolumn{2}{|c|}{$\begin{array}{l}\text { Affordable Charging } \\
\text { Time Range }\end{array}$} \\
\hline & & & \multirow{2}{*}{$\begin{array}{l}\text { Maximum } \\
\text { Affordability }\end{array}$} & \multirow{2}{*}{$\begin{array}{l}\text { Charging Option } \\
\text { Change Price }\end{array}$} & \multirow{2}{*}{$\begin{array}{c}\text { Remaining } \\
\text { Capacity (\%) }\end{array}$} & \multirow{2}{*}{$\begin{array}{c}\text { Maximum } \\
\text { Charging } \\
\text { Time (h) }\end{array}$} \\
\hline Gender & $\begin{array}{l}\text { Male } \\
\text { Female }\end{array}$ & & & & & \\
\hline Age & $\begin{array}{l}\text { Youth (18-38) } \\
\text { Middle-aged (38-58) } \\
\text { Elderly }(>58)\end{array}$ & & & & & \\
\hline EV type & $\begin{array}{l}\text { Small car } \\
\text { Medium-large car } \\
\text { Small SUV } \\
\text { Medium-large SUV } \\
\text { Others }\end{array}$ & & & & & \\
\hline
\end{tabular}

Table 1. Standard statistics summary table for the fast charging location selection of EV users.

\subsection{Cost-Sensitive User's Response to Charging Service Fees}

Since charging a service fee is irrelevant to the charging behaviors of Class I, II users, we will not discuss such cases in detail. For the Class III users who are sensitive to the cost, for them, it is necessary to balance the total charging time and total charging cost, and finally come to the decision of an optimal charging location for their own needs. Rational users will always pursue benefit maximization, so this paper analyzes this type of user by using the weighted decision model, and their charging location decision can be described as: 


$$
\begin{aligned}
X_{W s} & =\min \left\{X_{W i} \mid i=1,2, \cdots, n\right\} \\
& =\min \left\{\omega_{T} X_{T i}+\omega_{C} X_{C i} \mid i=1,2, \cdots, n\right\}
\end{aligned}
$$

where $X_{W s}$ is the weighted attribute value of $s$-th scheme chosen by the user after the trade-off; $X_{W i}$ is the weighted attribute value of $i$-th scheme; $X_{T i}$ is the total charging time attribute value of $i$-th scheme; $\omega_{T}$ is the weight of time attribute; $X_{C i}$ is the total charging cost of $i$-th scheme; $\omega_{C}$ is the weight of cost attribute; $n$ is the number of options for EV users.

Time and cost are two different dimensional, irrelevant attributes, so it is hard to directly weigh them. Considering that weighted attribute value $X_{W i}$ makes sense only when the schemes are compared, the enlargement and shrinkage of $X_{W i}$ will not affect the decision result. Therefore, the $X_{W i}$ time will be changed as the cost of time shown in Equation (6):

$$
X_{W i}^{\prime}=\frac{X_{W i}}{\omega_{C}}=\left(\frac{\omega_{T}}{\omega_{C}}\right) X_{T i}+X_{C i}=\alpha X_{T i}+X_{C i}
$$

where $\alpha$ is the unit time value (CNY/hour); $\alpha X_{T i}$ is time cost (CNY).

For EV users, the cost of time in the entire fast charging process means the total time from the time when demand is generated to when the charging process is finished. The key to determining the cost of time lies in the quantification of unit time value.

In present days, the time value for travelers is mainly determined by the production method, income method [18], etc. The former assumes that a traveler's travel time is used for production, so the increment is to be added to the national income or national production value. This method is used for assessing the working time value. The latter targets the traveler himself, and the value of time is measured according to certain percentage (time value coefficient) of the traveler's income. This method is generally used for assessing the leisure time value. Here, the income method is used to quantify the cost of time. The formula is:

$$
\alpha_{L}=k \frac{P_{p}}{T_{p}}
$$

where $\alpha_{L}$ is the unit travel time value corresponding to leisure time (CNY/hour); $k$ is the time value coefficient; $P_{p}$ is laborers' annual income (CNY); $T_{p}$ is laborers' annual working time (hours).

The time value coefficient in the income method is closely related to the national economic level, which is set at $20-25 \%$ by UK scholars, and is advised to be set as $25 \%$ by a French research report $[19,20]$. Due to way the Chinese market economy is constituted, the wage distribution system is incomplete, and some Chinese scholars believe that it should be set as 50\% [21].

When users judge among these schemes, they actually compare the difference among the weighted attribute values. Take case $i$ and case $j$ for instance, according to Equation (6), we have:

$$
\begin{aligned}
\Delta X_{W}{ }^{\prime} & =X_{W i}{ }^{\prime}-X_{W j}{ }^{\prime} \\
& =\left(\alpha X_{T i}+X_{C i}\right)-\left(\alpha X_{T j}+X_{C j}\right) \\
& =\alpha\left(X_{T i}-X_{T j}\right)+\left(X_{C i}-X_{C j}\right) \\
& =\alpha\left(X_{T i}-X_{T j}\right)+\left(\delta_{s e}+\delta_{s i}\right) C_{c a p}\left(1-S O C_{i}\right)-\left(\delta_{s e}+\delta_{s i}\right) C_{c a p}\left(1-S O C_{j}\right) \\
& \approx \alpha\left(X_{T i}-X_{T j}\right)+\left(\delta_{s i}-\delta_{s j}\right) C_{c a p}\left(1-S O C_{i}\right)
\end{aligned}
$$

where $\delta_{s e}$ is the unit price $(\mathrm{CNY} / \mathrm{kWh}) ; \delta_{s i}, \delta_{s j}$ is the charging service fee of the fast charge stations $i$ and $j$, respectively $(\mathrm{CNY} / \mathrm{kWh}) ; C_{c a p}$ is the battery capacity of vehicle $(\mathrm{kWh})$. When the difference $\Delta X_{W}{ }^{\prime}$ is greater than zero, the $j$-th scheme is the best solution. Otherwise, the $i$-th scheme is better.

As can be seen from Equation (8), regardless of the SOC when the vehicle arrives at the station by using different strategies, the user's response to charging service fees is the response to the service fee difference among charging stations. The higher the difference, the more likely that the user will abandon a shorter time strategy to pursue a more advantageous strategy in terms of price. 
For users who are in different locations, have different vehicle status and unit time value, their responses to the adjustment of charging service fee may not be the same. Therefore, it is necessary to carry out a personalized analysis. To be more specific, the coordinated guidance strategy based on the adjustment of charging service fees needs to be formulated in combination with specific fast charging demand distributions.

\section{Pricing Strategy of Charging Service Fees Based on Grid Benefits and Customer Satisfaction}

\subsection{The Adjustment of Charging Power Based on the Acceptable Node Voltage of FCS}

Considering the voltage variation characteristics of the distribution system, the PV curve can be drawn by using the continuous power flow method [22] to obtain the load power limit $P_{\mathrm{m}}$. However, the power limit is often used to analyze the system's voltage stability margin, and the system's normal operation point is very far from the critical point of the PV curve, thus, the power limit $P_{\mathrm{m}}$ cannot reflect the possible load access in the FCS. On the other hand, the normal operation of the distribution system needs to meets the constraints of power quality, and the load power corresponding to voltage amplitude limit (power quality constraint) can be obtained by PV curve, which is more stringent compared to the power limit $P_{\mathrm{m}}$ and is more likely to reflect the actual access of loads in the FCS. Therefore, the upper limit power $P_{\text {ssm }}$ constrained by the power quality of distribution system can be defined as the node tolerability D of the node where the FCS is located:

$$
D=P_{\mathrm{ssm}}
$$

the tolerability $D$ reflects the ability of FCS's receiving the fast charging loads.

Since charging piles are fixed, to take advantage of charging facilities and avoid EV users' waiting for too long, users' needs should be satisfied as much as possible. If the node voltage tolerability in distribution system during certain period is low, then the charging piles cannot provide full power charging for the EV users, but rather be reduced to avoid the bad effect on the distribution network.

According to the principle of equal distribution of the charging power, the charging power of each fast charging pile is shown in Equation (10):

$$
P_{i}=\min \left\{\frac{D}{n}, P_{\max }\right\}
$$

where $n$ is the number of fast piles that are being charged; $P_{\max }$ is the maximum fast charge power that can be provided by fast filling piles.

\subsection{Analysis of Grid Benefit and Customer Satisfaction Under Coordinated Fast Charging}

In this paper, the goal of coordinated fast charging is to equilibrate the charging loads in the region. Hence, the equilibrium degree of FCSs is used to evaluate the coordinated fast charging effectiveness. The charging capacity $A$ of the FCS is defined as:

$$
A=\min \left\{D, n P_{\max }\right\}
$$

It can be seen that the charging capacity of the FCS $A$ is different from the voltage tolerability $D$ of the power distribution system at the node where the FCS is located. After the completion of the FCS, the maximum access power of the fast charging loads is a rigid limit. The charging capacity $A$ of the FCS means the maximum access power of fast charging loads considering this rigid limit.

On this basis, the occupancy $U$ of the FCS is defined as:

$$
U=\frac{\sum_{i=1}^{M} C_{c a p i}\left(1-S_{O} C_{i}\right)}{A}
$$


In Equation (12), $\sum_{i=1}^{M} C_{c a p i}\left(1-S O C_{i}\right)$ indicates the sum of the charging demands of $M$ vehicles that need to be charged in the target period, and $A$ is the charging capacity of FCS. The occupancy $U$ reflects the charging density of FCS in the target period, indirectly reflecting the pressure of charging at this station. That is to say, the higher the occupancy $U$, the more the charging users and the higher the occupancy of charging piles, and the FCS is more likely to encounter queuing situation.

On the basis of occupancy $U$, the charging balance degree $E$ of each FCS is defined as (13):

$$
E=\min \left(U_{1}, U_{2}, \cdots, U_{i}, \cdots, U_{L}\right) / \max \left(U_{1}, U_{2}, \cdots, U_{i}, \cdots, U_{L}\right)
$$

where $L$ is the number of fast-charge stations within the target area; $U_{i}$ represents the occupancy of $i$-th fast-charge station.

The charging balance degree $E$ represents the difference of the access pressure at each FCS concerning the charging loads. The smaller the value of $E$, the more unbalanced the distribution of charging loads, and those stations with higher occupancy $U$ are more likely to be confronted with higher queuing risk, which is detrimental for both users and traffic. On the other hand, the greater the value of $E$, the more balanced the distribution of the charging loads, and the FCSs could satisfy the charging demands of the users and utilize the charging resources more effectively.

The charging balance degree $E$ can reflect the positive benefit obtained by the power grid at different degrees of coordinated fast charging. Therefore, this paper adopts this index to quantify and analyze the positive effect of coordinated fast charging.

From the perspective of users, the satisfaction degree is directly related to the users' charging cost and charging time. In this paper, the overall charging satisfaction degree is measured by the relative values of user's charging cost and the overall charging time. The calculation formulas are separately:

$$
\begin{aligned}
C_{i}^{*} & =\sum_{i=1}^{M} C_{i} / \sum_{i=1}^{M} C_{i 0} \\
T_{i}^{*} & =\sum_{i=1}^{M} T_{i} / \sum_{i=1}^{M} T_{i 0}
\end{aligned}
$$

where $C_{i}^{*}, T_{i}^{*}$ are the relative value of the overall charging cost and overall charging time, respectively; $C_{i 0}, C_{i}, T_{i 0}, T_{i}$ are the total cost of charging and the total charging time of user $i$ before and after charging service fee adjustment; $m$ is the total number of fast charging EV users.

The guidance effect of coordinated fast charging based on the adjustment of charging service fees can be evaluated by the above charging balance degree $E$, the user's overall charging $\operatorname{cost} C_{t}$ and the user's overall charging time $L_{t}$. Theoretically, the optimal scheme should maximize the charge balance degree $E$, minimize the relative value of user's overall charging time $T_{i}^{*}$, and the relative value of user's overall charging $\operatorname{cost} C_{i}^{*}$ should be reduced due to the reimbursement of FCSs. Taking into account the profitability and the enthusiasm of the user response, the benefits obtained from charging balance degree are quantified and parts of the benefits are returned to the users proportionally. The benefits mainly come from the reduced network loss, power expansion cost and reactive power compensation costs.

Obviously, to increase the charge balance degree $E$, more users have to change their original charging locations, so it is necessary to set larger range of charging service fee within the scope permitted by the policy to attract users to abandon the shorter time scheme but charge in the FCS with lowest fee. This process will in turn lead to the increase of user's overall charging time $T_{t}$, thus, the relative value of user's overall charging time $T_{i}^{*}$ increases.

It can be seen that the charging service fee is set as a multi-objective decision-making process when adjusting the charging service fee to coordinate fast charging demands. There exist conflicts among 
different targets, so the decision-maker needs to coordinate several indices to make comprehensive decisions when setting charging service fees.

\subsection{The Charging Service Fee Pricing Mechanism Considering the Equilibrium of FCS Loads Access and User Satisfaction}

From the analysis of Section 2.3, the selection of charging location for the price-sensitive users is largely dependent on the difference of charging service fees among FCSs. Therefore, the pricing mechanism of charging service fee can be divided into two steps: (1) coordinating the two objectives, namely the one that maximizes the charging balance degree $E$ and the one minimizes the relative value of overall charging time $T_{i}^{*}$, and determining the difference of service fees among various FCSs; (2) determining the service fees at each FCS based on the principle that the relative value of overall charging $\operatorname{cost} C_{i}^{*}$ will be slightly reduced due to the reimbursement from the grid. The flow chart is shown as Figure 1.

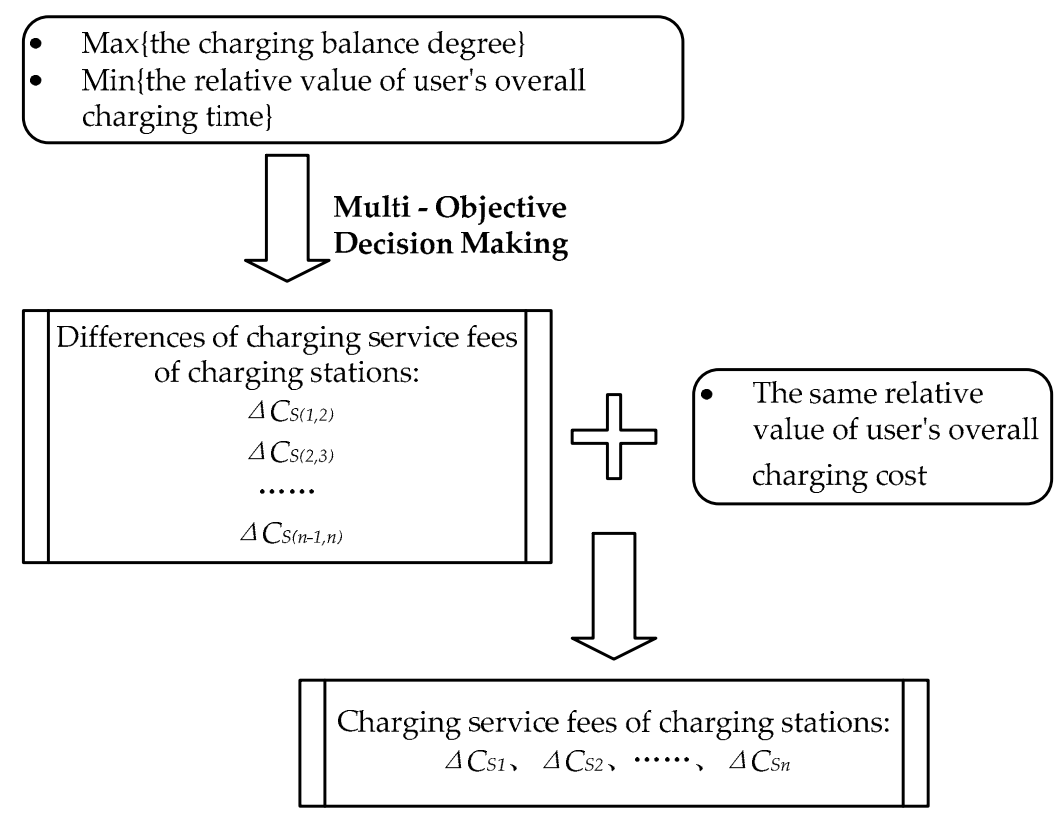

Figure 1. Flow chart of strategy devised for EV charging fees.

In this paper, we use Equations (16)-(18) to describe the multi-objective optimization model of the charging fees at each station:

$$
\begin{aligned}
& \max E=\frac{\min \left(U_{1}, U_{2}, \cdots, U_{L}\right)}{\max \left(U_{1}, U_{2}, \cdots, U_{L}\right)} \\
& \min T_{t}^{*}=\sum_{i=1}^{M} T_{i} / \sum_{i=1}^{M} T_{i 0} \\
& \text { s.t. }\left\{\begin{array}{l}
T_{i}=f_{i}(x) \quad i=1,2, \cdots, m \\
U_{j}=g_{j}(x) \quad j=1,2, \cdots, n
\end{array}\right.
\end{aligned}
$$

where $x$ is decision variable vector, namely the price difference between each two charging stations, $x=\left[\Delta C_{s(1,2)}, \Delta C_{s(2,3)}, \cdots, \Delta C_{s(n-1, n)}\right], f_{i}(x)$ is the total charging time function of user $i$ when the price difference is $x$, and this function correlates with the charging location selection with users, which can be calculated by Equation (1); $g_{j}(x)$ is the occupancy rate of station $j$ when the price difference is $x$, which can be calculated by Equation (12). 
It should be noticed that there exists a limit for the charging time $T_{i}$ of each EV to be charged: $T_{i}=\left[T_{i 0}, \Delta T_{\text {set }}\right]$, which means that we have $T_{i}=T_{i 0}$ when $\Delta T_{\text {set }}=0$ (ordinary constraint), and the value of $T_{i}$ varies from $\left(T_{i 0}-\Delta T_{\text {set }}\right)$ to $\left(T_{i 0}+\Delta T_{\text {set }}\right)$ when $\Delta T_{\text {set }}>0$ (fuzzy constraint).

The scenario in this paper is not a multi-objective linear programming problem but a multi-objective fuzzy programming problem, since the constraint condition of the total charging time is flexible. To this end, we first split the multi-objective programming into two single-objective programming problems. Take the process of setting the price differences between charging stations as example to illustrate the fuzzy programming [23].

Firstly, we fuzzify the constraints and the objective functions according to the fuzzy programming theory, then we construct the membership function of flexible constraint $\left(\Delta T_{\text {set }}>0\right)$ :

$$
A_{i}(x)=1-\frac{\left|T_{i}-T_{i 0}\right|}{\Delta T_{\text {set }}}, T_{i 0}-\Delta T_{\text {set }} \leq T_{i} \leq T_{i 0}+\Delta T_{\text {set }}
$$

where $T_{i}$ is a function that depends on decision variable $x$. We define the membership function of the ordinary constraint $\left(\Delta T_{\text {set }}=0\right)$ as:

$$
A_{i}(x)=1, T_{i}=T_{i 0}
$$

According to the definition of $A_{i}(x), \forall \lambda \in[0,1], A_{i}(x) \geq \lambda$ is equivalent to:

$$
\Delta T_{\text {set }} \lambda-\Delta T_{\text {set }} \leq T_{i}-T_{i 0} \leq \Delta T_{\text {set }}-\lambda \Delta T_{\text {set }}, i=1,2, \ldots, m
$$

Assuming that the optimal value of the ordinary linear programming $\max E=\frac{\min \left(U_{1}, U_{2}, \cdots, U_{n}\right)}{\max \left(U_{1}, U_{2}, \cdots, U_{n}\right)}$, $T_{i}=T_{i 0}$ is $f_{0}$. The optimal value of $\max E=\frac{\min \left(U_{1}, U_{2}, \cdots, U_{n}\right)}{\max \left(U_{1}, U_{2}, \cdots, U_{n}\right)}, T_{i 0}-\Delta T_{\text {set }} \leq T_{i} \leq T_{i 0}+\Delta T_{\text {set }}$ is $f_{1}$. We define $\Delta E_{0}=f_{0}-f_{1}$, thus, the membership function of the objective function in this fuzzy programming is:

$$
G_{i}(x)=\frac{f_{0}-E}{\Delta E_{0}}, f_{0}-\Delta E_{0} \leq E \leq f_{0}
$$

According to the definition of $G_{i}(x), \forall \lambda \in[0,1], G_{i}(x) \geq \lambda$ is equivalent to:

$$
E+\Delta E_{0} \lambda \leq f_{0}
$$

Therefore, the fuzzy programming of $\max E=\frac{\min \left(U_{1}, U_{2}, \cdots, U_{n}\right)}{\max \left(U_{1}, U_{2}, \cdots, U_{n}\right)}, T_{i}=\left[T_{i 0}, \Delta T_{\text {set }}\right]$ can be transformed into ordinary linear programming problems:

$$
\left\{\begin{array}{l}
\max \lambda \\
\text { s.t. }\left\{\begin{array}{l}
E+\Delta E_{0} \lambda \leq f_{0} \\
\Delta T_{\text {set }} \lambda-\Delta T_{\text {set }} \leq T_{i}-T_{i 0} \leq \Delta T_{\text {set }}-\lambda \Delta T_{\text {set }} \\
i=1,2, \ldots, \mathrm{m}
\end{array}\right.
\end{array}\right.
$$

The solution obtained by fuzzy programming is a perfect solution of the multi-objective programming model.

The abovementioned single-objective programming problem, which contains multiple abstract functions, is difficult to solve with the analytical method. Therefore, a genetic algorithm is adopted to solve the above programming problem, whose solution steps are shown in Figure 2. 


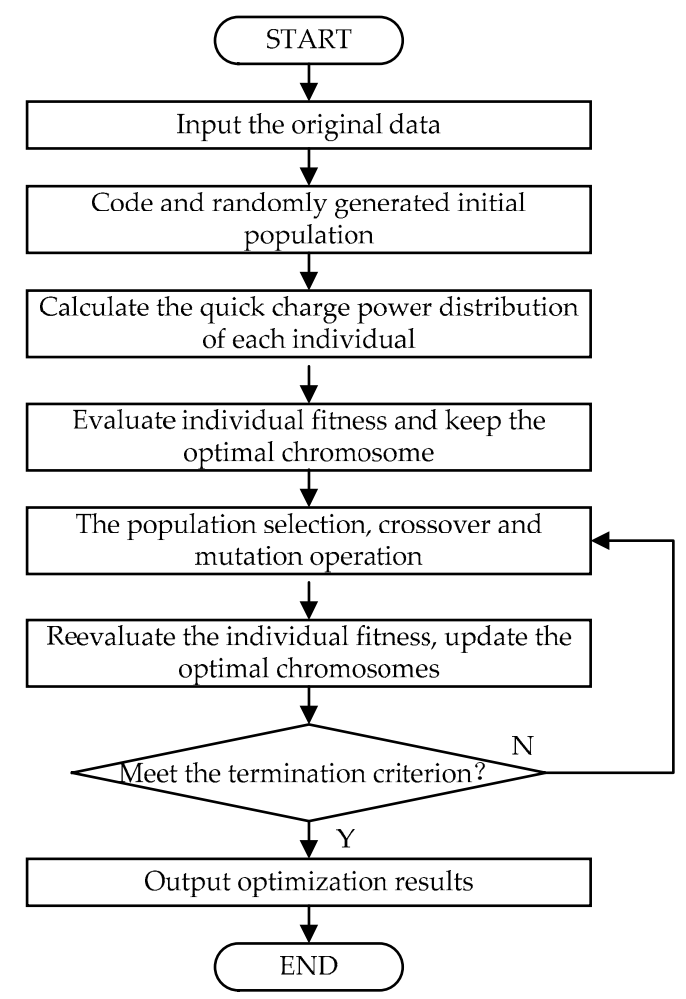

Figure 2. Flow chart of genetic algorithm for solving the single-target programming problem.

Combining the genetic algorithm and the fuzzy programming method, the satisfactory solution of the service fee differences can be obtained by fuzzy programming.

According to a user's overall charging cost, the calculation of the service fees of charging stations can be completed then. The corresponding single-objective optimization model is shown as follows:

$$
\begin{gathered}
\min \left|\sum_{i=1}^{M}\left[C_{i}-\left(C_{i 0}-C_{R}\right)\right]\right| \\
\text { s.t. }\left\{\begin{array}{l}
C_{i}=h_{i}(x) \\
x(j)-x(k)=\Delta x_{j, j+1}+\Delta x_{j+1, j+2}+\cdots+\Delta x_{k-1, k} \\
i=1,2, \cdots, m ; j=1,2, \cdots, n ; \\
j<k ;
\end{array}\right.
\end{gathered}
$$

where $x$ is the decision variable, that is the service fee at each FCS, $x \equiv\left[C_{S(1)}, C_{S(2)}, \cdots, C_{S(n)}\right] . C_{i}$ is the overall charging cost within the target area after the adjustment of charging service fee; $C_{i 0}$ is the overall charging cost within the target area before the adjustment of charging service fee; $C_{R}$ is the reimbursement for the system. $x(j)$ is the charging service fee for the $j$-th FCS, that is $x(j)=C_{S(j)}$; $\Delta x_{j, j+1}$ is the difference of charging service fee between $j$-th and $j+1$-th FCSs, which has been calculated in the previous steps; $h_{i}(x)$ is the function of overall charging cost for the $i$-th user when the charging service fee in each station is $x$, which is an abstract function.

The problem can also be solved by using the genetic algorithm. Eventually, the charging service fee at each FCS can be obtained. 


\section{Example Simulation}

\subsection{Simulation Idea and Data Sources Explaination}

Based on the distribution of fast charging demands in the target region, combined with different types of user charging selection criteria, this paper employs a fuzzy programming algorithm to achieve the multi-objective optimization of charging balance degree and user satisfaction degree, and then the charging service fee at each FCS is calculated and the changes of the indexes before and after cost adjustment can be obtained.

Before the popularization of EVs and ITS, the geographical locations and battery states of EVs in the road network cannot be recorded and accessed in real-time. In order to obtain the distribution of fast charging demands in the target region, this paper randomly generates the geographical locations and battery states of EVs in the road network (see Appendix A), according to the geographical locations and remaining fuel state of the fuel vehicles in one evening peak in a specific road network system. Actually, in the future, with a myriad of EVs' access to ITS system, the geographical locations and battery states of EVs in the road network can be acquired in real-time.

Through the statistical analysis of the behavior characteristics of EV users, we can compile the statistical summary table shown in Table 1 in Section 2.2, and adopt the disaggregate MNL model to obtain the probability of users adopting various charging location selection criteria. However, the current number of EVs is limited, despite of a wide range of data collection based on Table 1. Thus, the statistical results still cannot characterize the future large-scale EVs' access scenario. Considering that the selection of the charging locations for EV users is similar to the selection of the charging location for the fuel vehicles, the statistical data in this paper for each factor (shown in Table 1) is obtained by adopting MNL model on the basis of the travel characteristics of the fuel vehicles in the existing road network. As a result, the ratio of users Class I, II and III in the target region is about 2:3:5.

In summary, due to the lack of relevant data, in the following simulation example, the given basic data such as the geographical locations and battery states of EVs in the road network, and the probability of different EV users adopting various types of charging location selection criteria are formed according to the existing traffic network and fuel vehicle distribution. However, the goal of this attempt is only to test and verify the methods and the effectiveness of the charging load scheduling strategy mentioned in this paper. Theoretically, whether the relevant data and the future scenario are mutually fitted will only affect the final assessment of the size of the specific indexes, but this will not change the equilibrium trend of charging loads before and after the adjustment of the charging service fee.

It is necessary to use a more reliable method for the simulation of arrival of vehicles, waiting time in queue for recharge, state of charge of the battery, etc. Therefore, this paper uses the Monte Carlo method to simulate the dynamic process of the EV's spatial-temporal distribution [24].

\subsection{Parameters Setting and Simulation Calculation}

The region shown in Figure 3 is used as the analysis object, the figure shows the main road traffic network in the target region, the two FCSs are located in point $\mathrm{A}$ and $\mathrm{B}$, the pull-in direction is shown in Figure 3, where the distance between station A and intersection 11 is 220 meters and the distance between station B and intersection 25 is 380 meters. All roads are two-way lanes, and vehicles can only turn around at the intersections. The FCS A is located at node 23 of the IEEE 33 node distribution system shown in Figure 4, and the FCS B is located at node 7 of distribution system shown in Figure 4, the number of fast charging piles in these two stations is 20 and 30 respectively, and the maximum charging power is $80 \mathrm{~kW}$ and the power factor is $98 \%$. The unit price is $0.87 \mathrm{CNY} / \mathrm{kWh}$, and before the charging service fee based coordinated fast charging strategy being implemented, the charging fee in these two stations is $1 \mathrm{CNY} / \mathrm{kWh}$. Taking the targeted time period 20:00-22:00 as an example, there are 80 fast charging demands, whose spatial distribution is shown in Figure 3 (the fast charging demands are related to the traffic flow, the higher the traffic flow, the more the distribution of charging 
demands). The geographical locations and battery states of EVs to be charged in the simulation region are shown in Table A1 in Appendix A.

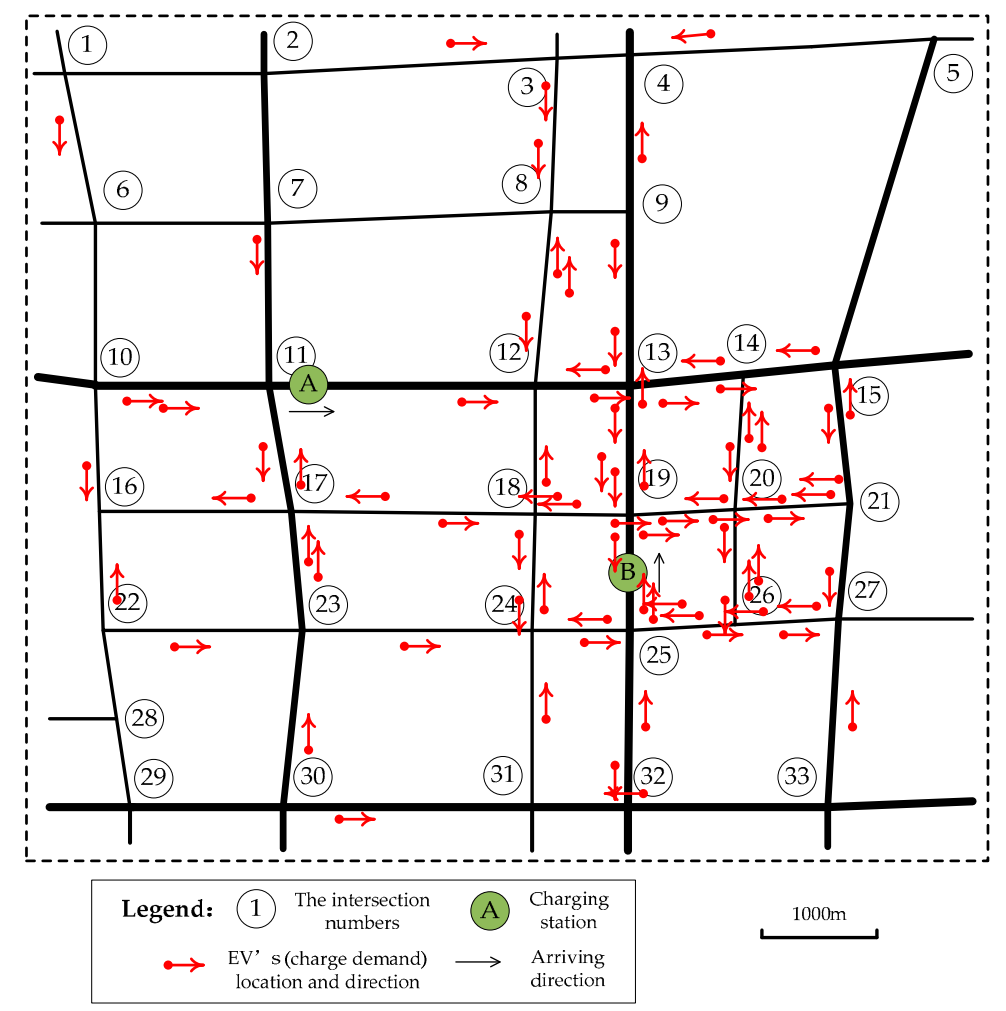

Figure 3. Sketch of the transportation network in the object region.

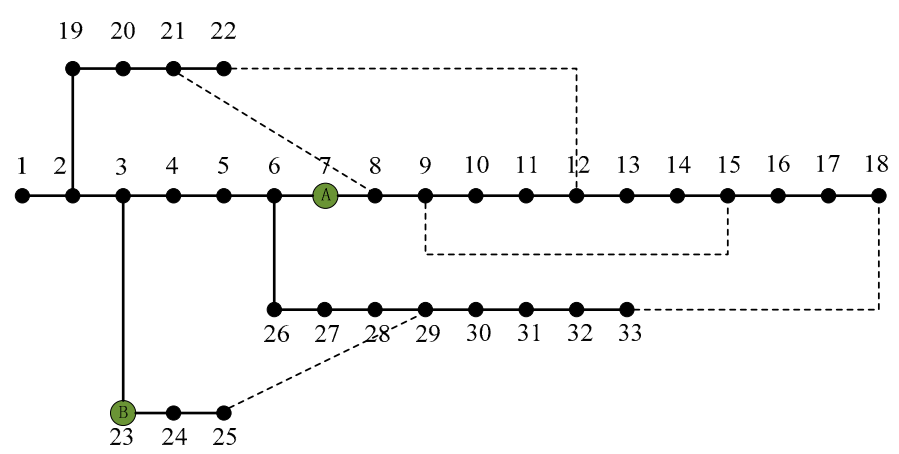

Figure 4. Structure of the IEEE-33 distribution system.

The unit time value of users can be calculated by the per capita income in the targeted region according to Equation (7), and it is set to $20 \mathrm{CNY} /$ hour in this case.

As the charging location selection results vary with different types of users, considering the user choice probability, for a single user, the expected values of the total charging time and the total charging cost are:

$$
\begin{aligned}
& \bar{T}=p_{I} T_{I}+p_{I I} T_{I I}+p_{I I I} T_{I I I} \\
& \bar{C}=p_{I} C_{I}+p_{I I} C_{I I}+p_{I I I} C_{I I I}
\end{aligned}
$$

where $\bar{T}$ is the expected value of total charging time for the user, $\bar{C}$ is the expected value of the total charging cost for the user. $p_{I}, p_{I I}, p_{I I I}$ are the probability for Class I, Class II and Class III type users, respectively. $T_{I}, T_{I I}, T_{I I I}$ are the total charging time for Class I, Class II and Class III type users, 
respectively. $C_{I}, C_{I I}, C_{I I I}$ are the total charging cost in optimal charging location for Class I, Class II and Class III type users, respectively. For FCSs, the expected value of total charging volume in the target period is:

$$
\overline{E p_{i}}=\sum_{j=1}^{m} \sum_{k=I}^{I I I} p_{k} I_{j, k, i} C_{c a p j}\left(1-S O C_{j, i}\right)
$$

where, $\overline{E p_{i}}$ is the expected value for total charging volume at charging station $i ; p_{k}$ is the probability of $k$-th ( $k=\mathrm{I}$, II and III) type of users; $I_{j, k, i}$ is the charging location selection coefficient, whose value is set as 1 when the $j$-th $(j=1, \ldots, m)$ user is the $k$-th type of users, and its optimal charging location is charging station $i$, otherwise is set as $0 ; C_{c a p j}$ is the battery capacity for the $j$-th user; $S O C_{j, i}$ is the remaining SOC when the $j$-th user arrives at charging station $i$.

When the charging service fee is not adjusted, combined with the above-mentioned user response mode, the expected value of the charging balance degree $\overline{E_{0}}$ can be calculated according to Equations (11)-(15), (26)-(28), thus $\overline{E_{0}}=0.2811$.

Similarly, the expected value of charging balance degree and the relative expected values of overall charging time and overall charging cost of station A and B under different charging service fees can be calculated, the results are shown in Figure 5.

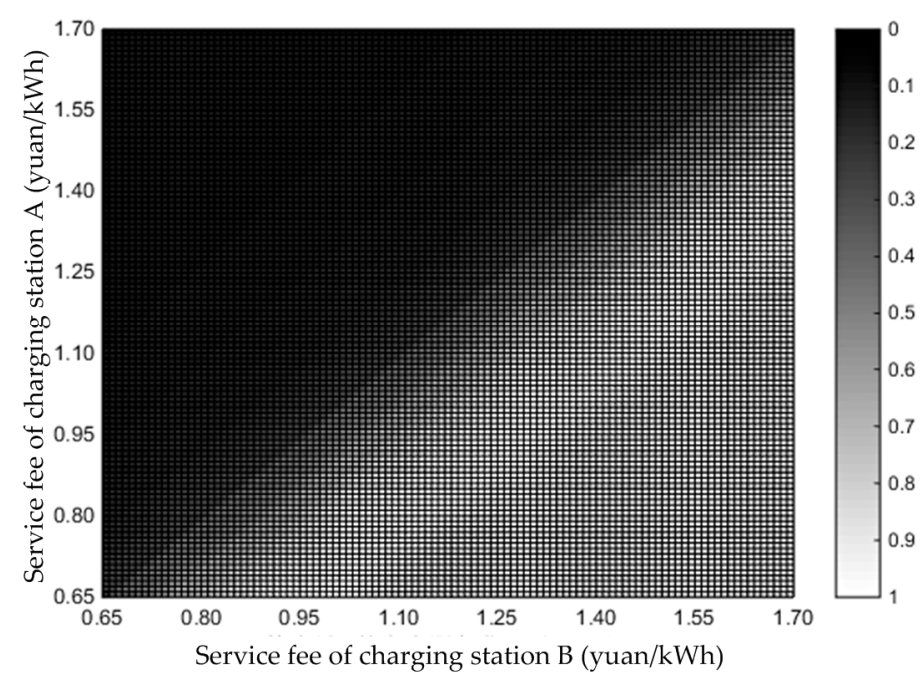

Figure 5. Expected value of charging balance in different charging service fees.

Figure 5 aims to explain the relationship between the charging balance degree $E$ and the charging fees of different stations. In the upper-left and lower-right section of Figure 5, due to the large difference in charging fee between the two stations, EV users are more likely to choose the one with lower cost. Under this circumstance, the value of $E$ in these two sections are much larger, which reflects an unbalance of the charging load distribution.

The acceptable range of the charge balance degree is $E \geq 0.8$; and the acceptable range of the relative value of users' overall charging time is $T_{i}^{*} \leq 1.15$; Due to EV users' response toward the charging cost, the charging balance degree in the target region increases, the voltage of each node in the distribution system is more balanced, the network loss is reduced, and the additional capacity and reactive power compensation at fast charging nodes become smaller, thus the economic benefit of the power grid is improved (this paper does the initial accounting aimed mainly at the reactive power equipment investment operating costs). However, the EV users' overall charging time increases. To ensure the user benefits, grid companies or FCSs should reimburse part of the benefits to users to reduce their overall charging cost. The amount of reimbursement will directly affect the user dependency, but it will not be analyzed in detail here due to space limitations. 
This paper only assumes that the amount of reimbursement of the grid is $2 \%$ of the total charging cost, and the relative value of users' overall charging cost is maintained as $C_{i}^{*} \approx 0.98(0.978-0.982)$, Based on Figure 5, the feasible range of charging service fee of these two FCSs is shown in Figure 6.

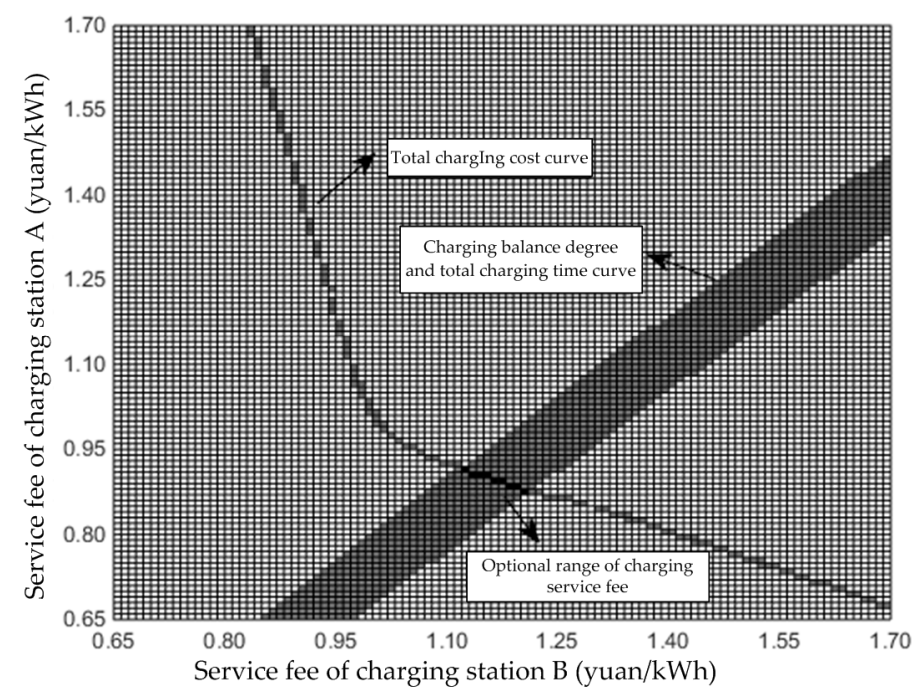

Figure 6. Feasible domain of charging service fees.

Using the genetic algorithm and fuzzy programming method, the satisfactory solutions of charging service fee for station $\mathrm{A}$ and $\mathrm{B}$ are $0.89 \mathrm{CNY} / \mathrm{kWh}$ and $1.17 \mathrm{CNY} / \mathrm{kWh}$, respectively. In this scenario, the grid benefit (the relative charging balance degree of FCSs in the target region $\bar{E}^{\prime}$ ) and user satisfaction degree (the relative values of users' overall charging time ${\overline{T_{t}^{*}}}^{\prime}$ and charging $\operatorname{cost} \overline{C_{t}^{*}}$ ) are separately:

$$
\bar{E}^{\prime}=0.9211,{\overline{T_{t}^{*}}}^{\prime}=1.1297,{\overline{C_{t}^{*}}}^{\prime}=0.981
$$

Hence, the grid balance degree increases from 0. 2811 to 0.9211 after the adjustment of charging service fee, the distribution of charging loads becomes more uniform, and the charging infrastructures are fully utilized. However, the users' overall charging time has slightly increased by $12.97 \%$, but the users' overall charging time has reduced by $1.9 \%$, considering various types of users, a large proportion of users are price-sensitive, they are willing to pay a certain amount of time cost to obtain the charging benefits. Therefore, users are more likely to accept such coordinated fast charging strategy and the node voltage over-limit and voltage offset volume in the IEEE 33 system at this moment is shown in Table 2.

Table 2. Voltage off-limit situation in IEEE-33 system.

\begin{tabular}{ccc}
\hline Scenes & The Over-Limit Voltage Node & $\begin{array}{c}\text { The Most Serious Voltage } \\
\text { Offset Value (Per Unit Value) }\end{array}$ \\
\hline Random access of charging load & $\begin{array}{c}9,10,11,12,13,14,15,16,17,18, \\
28,29,30,31,32,33\end{array}$ & 0.919573 \\
\hline $\begin{array}{c}\text { Change the charging fees to } \\
\text { regulate EVs }\end{array}$ & $13,14,15,16,17,18,30,31,32,33$ & 0.921568 \\
\hline
\end{tabular}

According to the requirement [25], the limitation of power supply voltage offset should be " $20 \mathrm{kV}$ and below three phase power supply voltage offset should be $\pm 7 \%$ of nominal voltage" (China national standardization management committee, 2008).

It can be seen from Table 2 that after the adjustment of charging service fees, the range of off-limit voltage nodes is reduced, the voltage offset is also reduced, and thus less reactive power compensation equipment is required. However, due to the large access of charging loads to the grid, these two 
scenarios both encounter the problems of off-limit voltage and reactive power deficiency when the grid is operating in the peak-load period, and additional reactive power compensation devices are required.

Static var generator (SVG) is the third generation reactive power compensation device after SVC [26]. It has the advantages of long life span, high stability, fast response and low harmonic content. This paper assumes that the reactive power deficiency is provided by SVG, whose cost accounting method is shown in Table A2 in Appendix A. The reactive power compensation investment costs after the adjustment of charging service fee is shown in Table 3 after calculation.

Table 3. Cost of reactive-load compensation equipment before and after charging fee adjustment.

\begin{tabular}{ccccc}
\hline Scenes & $\begin{array}{c}\text { Configuration } \\
\text { Capacity of Reactive } \\
\text { Power Compensation } \\
\text { Device (Mvar) }\end{array}$ & $\begin{array}{c}\text { Initial Investment Cost } \\
\text { (Ten Thousand CNY) }\end{array}$ & $\begin{array}{c}\text { The Most Serious } \\
\text { Annual Operating Costs } \\
\text { (Ten Thousand CNY) }\end{array}$ & $\begin{array}{c}\text { Voltage Offset Value } \\
\text { after Reactive } \\
\text { Compensation } \\
\text { (Per Unit Value) }\end{array}$ \\
\hline $\begin{array}{c}\text { Random access of } \\
\text { charging load }\end{array}$ & 9.6 & 324 & 23.6 & 0.9373 \\
\hline $\begin{array}{c}\text { Change the } \\
\text { charging fees to } \\
\text { regulate EVs }\end{array}$ & 7 & 220 & 18 & 0.9427 \\
\hline
\end{tabular}

As can be seen from Table 3, for the $10 \mathrm{kV}$ distribution system given in the simulation case, through the adjustment of charging service fee, the cost of initial reactive power equipment can be effectively reduced by 1.04 million CNY, and the annual operating cost is reduced by $56,000 \mathrm{CNY}$.

Taking into consideration that the penetration of EVs is relatively small nowadays, there are only two FCSs being designed in the distribution network of the simulation system, and only 80 fast charging demands are generated during the peak-load period. With the rapid development of EVs, the number of FCSs and fast charging demands will increase continually, and considerable economic and social benefits will be brought by the use of charging service fees to orderly guide the charging behaviors.

\section{Conclusions}

This paper has proposed a price-setting strategy concerning the charging service fee at FCSs by considering both the charging balance degree and user satisfaction degree in the target region. This method first adjusts the charging service fee to guide the fast charging behaviors of EVs in the spatial dimension, and balances the fast charging loads at each charging station while ensuring user satisfaction degree. Taking the IEEE 33 nodes distribution network and the corresponding road network system as an example, based on the fast charging demand distribution in the target region, the price-setting of charging service fee at each FCS and the orderly guidance of fast charging loads are achieved. Finally, the simulation results show that the adjustment of charging service fee can effectively dispatch the distribution of fast loads at the spatial level, can improve the local charging balance degree, and can be easily implemented due to its good user satisfaction degree.

It should be noted that currently, the safety and reliability evaluation system of EV-included distribution network is not mature, and the impact of fast charging loads' large-scale random access to distribution networks (including power quality, power flow distribution, voltage offset, overloading) requires further study. On the other hand, the access of charging loads will cause the increase of backup power, transformer capacity and reactive power compensation equipment investment. Thus, the economic costs need to be further analyzed. This paper only considers the charging balance degree as the evaluation index of the distribution network, which has certain limitations. In conclusion, the determination of the reimbursement scale of the system after the equilibrium of the charging loads still needs to be refined and such problems are definitely the focus of future research.

It's the future development tendency to combine the charging stations with renewable energy power generations, which can economize on energy and reduce discharge. Under this circumstance, we should consider the following problems: 
- Energy storage devices must be implemented to deal with the stochasticity and fluctuation of renewable energy resources. By making cascade utilization of the lithium batteries of EV, we can minimize the cost of the acquisition cost and discard cost of lithium batteries. Therefore, it's worthy to research the collaborative planning of charging service fees and battery exchange fees setting.

- To encourage more EV users to adopt renewable energy resources, the charging fees at the renewable energy charging stations can be more favorable or free at specific moments. Thus, it's worthy to study the charging fee setting of ordinary charging stations and renewable energy charging stations by considering the generation cost of thermal and hydro units and output characteristics of new energy resources at different moments.

Due to length limitations, we cannot solve the aforementioned problems within this paper, which will be explored in later research.

Acknowledgments: Project supported by National Natural Science Foundation of China (51537003).

Author Contributions: All the participants have contributed a lot to the formation of this paper. Shu Su has come up with the essential idea for this paper, and Hang Zhao went a step further to adding specific details to this idea, such as employing the $\mathrm{M} / \mathrm{M} / \mathrm{C}$ queuing theory and fuzzy programming method into this model. Hongzhi Zhang carried out the simulation in MATLAB and verified the correctness of this method, Xiangning Lin gave guidance and provided technical assistance during the course.

Conflicts of Interest: The authors declare no conflict of interest. And the founding sponsors had no role in the design of the study; in the collection, analyses, or interpretation of data; in the writing of the manuscript, and in the decision to publish the results. 


\section{Appendix A}

Table A1. Location and battery capacity of fast charging users in the target area.

\begin{tabular}{|c|c|c|c|c|c|c|c|c|c|c|c|}
\hline \multirow[b]{2}{*}{$\begin{array}{l}\text { EV } \\
\text { Num. }\end{array}$} & \multicolumn{3}{|c|}{ EV Location } & \multicolumn{2}{|c|}{ Battery Parameter } & \multirow[b]{2}{*}{$\begin{array}{l}\text { EV } \\
\text { Num. }\end{array}$} & \multicolumn{3}{|c|}{ EV Location } & \multicolumn{2}{|c|}{ Battery Parameter } \\
\hline & $\begin{array}{l}\text { The Previous } \\
\text { Intersection } \\
\text { Numbers }\end{array}$ & $\begin{array}{l}\text { The Next } \\
\text { Intersection } \\
\text { Numbers }\end{array}$ & $\begin{array}{l}\text { Distance from } \\
\text { the Next } \\
\text { Intersection } / \mathbf{k m}\end{array}$ & $\begin{array}{c}\text { Battery } \\
\text { Capacity/kWh }\end{array}$ & $\begin{array}{l}\text { State of } \\
\text { Charge }\end{array}$ & & $\begin{array}{l}\text { The previous } \\
\text { Intersection } \\
\text { Numbers }\end{array}$ & $\begin{array}{l}\text { The Next } \\
\text { Intersection } \\
\text { Numbers }\end{array}$ & $\begin{array}{l}\text { Distance from } \\
\text { the Next } \\
\text { Intersection } / \mathrm{km}\end{array}$ & $\begin{array}{c}\text { Battery } \\
\text { Capacity/kWh }\end{array}$ & $\begin{array}{l}\text { State of } \\
\text { Charge }\end{array}$ \\
\hline 1 & 2 & 3 & 0.91 & 18 & 0.39 & 41 & 18 & 19 & 0.12 & 42 & 0.34 \\
\hline 2 & 5 & 4 & 0.73 & 33 & 0.50 & 42 & 20 & 19 & 0.82 & 33 & 0.33 \\
\hline 3 & 1 & 6 & 0.96 & 12 & 0.17 & 43 & 19 & 20 & 0.24 & 15 & 0.38 \\
\hline 4 & 3 & 8 & 0.52 & 26 & 0.42 & 44 & 19 & 20 & 0.63 & 18 & 0.38 \\
\hline 5 & 3 & 8 & 1.05 & 38 & 0.38 & 45 & 19 & 20 & 0.78 & 38 & 0.28 \\
\hline 6 & 9 & 4 & 0.98 & 26 & 0.25 & 46 & 21 & 20 & 0.44 & 15 & 0.35 \\
\hline 7 & 7 & 11 & 1.20 & 15 & 0.32 & 47 & 21 & 20 & 0.87 & 15 & 0.34 \\
\hline 8 & 8 & 12 & 0.64 & 18 & 0.38 & 48 & 21 & 20 & 0.93 & 12 & 0.40 \\
\hline 9 & 12 & 8 & 0.53 & 12 & 0.64 & 49 & 20 & 21 & 0.74 & 26 & 0.44 \\
\hline 10 & 12 & 8 & 0.74 & 18 & 0.57 & 50 & 22 & 16 & 0.78 & 42 & 0.44 \\
\hline 11 & 9 & 13 & 0.48 & 26 & 0.24 & 51 & 23 & 17 & 0.43 & 15 & 0.28 \\
\hline 12 & 9 & 13 & 1.31 & 12 & 0.59 & 52 & 23 & 17 & 0.54 & 33 & 0.36 \\
\hline 13 & 10 & 11 & 1.27 & 90 & 0.41 & 53 & 18 & 24 & 0.27 & 70 & 0.25 \\
\hline 14 & 10 & 11 & 0.93 & 26 & 0.34 & 54 & 18 & 24 & 0.82 & 26 & 0.26 \\
\hline 15 & 11 & 12 & 0.69 & 42 & 0.41 & 55 & 24 & 18 & 0.85 & 15 & 0.35 \\
\hline 16 & 13 & 12 & 0.65 & 15 & 0.33 & 56 & 19 & 25 & 0.83 & 18 & 0.47 \\
\hline 17 & 12 & 13 & 0.38 & 15 & 0.34 & 57 & 25 & 19 & 0.85 & 42 & 0.29 \\
\hline 18 & 14 & 13 & 0.81 & 33 & 0.47 & 58 & 25 & 19 & 0.93 & 38 & 0.38 \\
\hline 19 & 13 & 14 & 0.22 & 18 & 0.46 & 59 & 20 & 26 & 0.22 & 15 & 0.33 \\
\hline 20 & 13 & 14 & 0.75 & 15 & 0.46 & 60 & 20 & 26 & 0.89 & 26 & 0.44 \\
\hline 21 & 15 & 14 & 0.64 & 42 & 0.40 & 61 & 26 & 20 & 0.73 & 12 & 0.26 \\
\hline 22 & 10 & 16 & 0.38 & 18 & 0.25 & 62 & 26 & 20 & 0.64 & 15 & 0.35 \\
\hline 23 & 11 & 17 & 0.62 & 15 & 0.41 & 63 & 21 & 27 & 0.42 & 26 & 0.39 \\
\hline 24 & 17 & 11 & 0.88 & 33 & 0.48 & 64 & 22 & 23 & 1.15 & 26 & 0.44 \\
\hline 25 & 18 & 12 & 0.80 & 26 & 0.39 & 65 & 23 & 24 & 1.09 & 15 & 0.47 \\
\hline 26 & 13 & 19 & 0.37 & 12 & 0.43 & 66 & 25 & 24 & 0.68 & 42 & 0.36 \\
\hline 27 & 13 & 19 & 0.49 & 26 & 0.41 & 67 & 24 & 25 & 0.43 & 15 & 0.23 \\
\hline 28 & 13 & 19 & 0.92 & 18 & 0.33 & 68 & 26 & 25 & 0.47 & 15 & 0.29 \\
\hline 29 & 19 & 13 & 0.17 & 12 & 0.37 & 69 & 26 & 25 & 0.58 & 33 & 0.27 \\
\hline 30 & 19 & 13 & 0.86 & 18 & 0.29 & 70 & 25 & 26 & 0.30 & 26 & 0.54 \\
\hline 31 & 14 & 20 & 0.53 & 15 & 0.42 & 71 & 27 & 26 & 0.27 & 12 & 0.30 \\
\hline
\end{tabular}


Table A1. Cont.

\begin{tabular}{|c|c|c|c|c|c|c|c|c|c|c|c|}
\hline \multirow[b]{2}{*}{$\begin{array}{l}\text { EV } \\
\text { Num. }\end{array}$} & \multicolumn{3}{|c|}{ EV Location } & \multicolumn{2}{|c|}{ Battery Parameter } & \multirow[b]{2}{*}{$\begin{array}{l}\text { EV } \\
\text { Num. }\end{array}$} & \multicolumn{3}{|c|}{ EV Location } & \multicolumn{2}{|c|}{ Battery Parameter } \\
\hline & $\begin{array}{l}\text { The Previous } \\
\text { Intersection } \\
\text { Numbers }\end{array}$ & $\begin{array}{l}\text { The Next } \\
\text { Intersection } \\
\text { Numbers }\end{array}$ & $\begin{array}{l}\text { Distance from } \\
\text { the Next } \\
\text { Intersection } / \mathbf{k m}\end{array}$ & $\begin{array}{c}\text { Battery } \\
\text { Capacity/kWh }\end{array}$ & $\begin{array}{l}\text { State of } \\
\text { Charge }\end{array}$ & & $\begin{array}{l}\text { The previous } \\
\text { Intersection } \\
\text { Numbers }\end{array}$ & $\begin{array}{l}\text { The Next } \\
\text { Intersection } \\
\text { Numbers }\end{array}$ & $\begin{array}{l}\text { Distance from } \\
\text { the Next } \\
\text { Intersection } / \mathbf{k m}\end{array}$ & $\begin{array}{c}\text { Battery } \\
\text { Capacity/kWh }\end{array}$ & $\begin{array}{l}\text { State of } \\
\text { Charge }\end{array}$ \\
\hline 32 & 20 & 14 & 0.52 & 15 & 0.26 & 72 & 27 & 26 & 0.73 & 18 & 0.41 \\
\hline 33 & 20 & 14 & 0.61 & 38 & 0.26 & 73 & 26 & 27 & 0.48 & 38 & 0.33 \\
\hline 34 & 15 & 21 & 0.85 & 15 & 0.29 & 74 & 30 & 23 & 1.01 & 26 & 0.42 \\
\hline 35 & 21 & 15 & 0.44 & 12 & 0.11 & 75 & 31 & 24 & 0.77 & 33 & 0.29 \\
\hline 36 & 17 & 16 & 1.38 & 15 & 0.47 & 76 & 25 & 32 & 0.35 & 38 & 0.24 \\
\hline 37 & 18 & 17 & 0.79 & 33 & 0.38 & 77 & 32 & 25 & 0.83 & 15 & 0.24 \\
\hline 38 & 17 & 18 & 0.81 & 70 & 0.29 & 78 & 33 & 27 & 0.97 & 18 & 0.39 \\
\hline 39 & 19 & 18 & 0.23 & 26 & 0.46 & 79 & 30 & 31 & 1.66 & 26 & 0.34 \\
\hline 40 & 19 & 18 & 0.39 & 26 & 0.21 & 80 & 33 & 32 & 0.13 & 18 & 0.33 \\
\hline
\end{tabular}

Table A2. Cost accounting table of investment and maintenance for SVG in distribution network.

\begin{tabular}{|c|c|c|c|c|c|}
\hline Distribution Voltage Level (kV) & SVG Capacity (MVar) & Rated Service Life (year) & $\begin{array}{l}\text { Investment Costs } \\
\text { (Ten Thousand CNY) }\end{array}$ & $\begin{array}{l}\text { Annual Operation Cost } \\
\text { (Ten Thousand CNY) }\end{array}$ & Industry Discount Rate (\%) \\
\hline 3.8 & 0.3 & 18 & 7 & 0.8 & 15 \\
\hline 3.8 & 1 & 18 & 50 & 2 & 15 \\
\hline 10 & 2 & 18 & 70 & 5 & 15 \\
\hline
\end{tabular}


Through the sample study of the service objects and the arrival time, the statistical law of the quantity index (like waiting time, queue length, service intensity, etc.) of the system is available and can be used to reconstruct the process of service delivery and ensure the agency's cost or some other indicators, thus achieving multi-objective optimization. EVs' charging service behaviors are mutually independent, which meet the characteristics of stationarity, non-aftereffect property and generality. The $\mathrm{M} / \mathrm{M} / \mathrm{c}$ queuing theory is employed to calculate the waiting time of electrical vehicle users spend before getting charged. And the queuing process is shown in Figure A1:

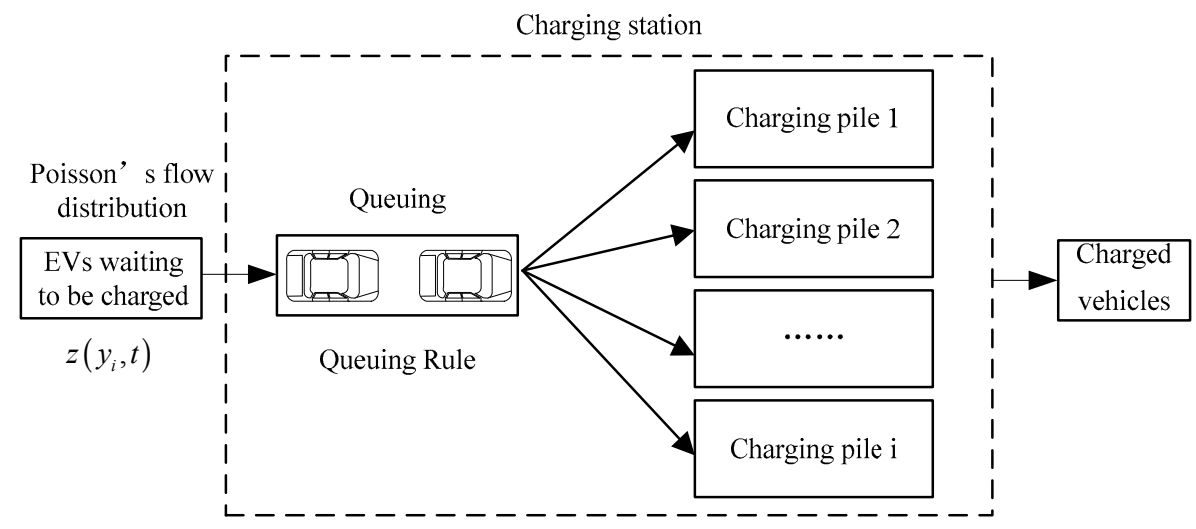

Figure A1. Queuing model of charging station based on the M/M/s model.

In order to calculate the queuing time of the electric vehicle users in the charging stations, the following assumptions are made:

1. The arrival pattern of the cars waiting to be charged is subject to Poisson's flow distribution with parameter $\lambda(\lambda>0)$;

2. The charging service time required of each vehicle is independent and obeys a negative exponential distribution with parameter $\mu(\mu>0)$;

3. The charging station has $c(c \geq 1)$ charging equipment which can provide service independently and concurrently;

4. The first-come first-served rule is executed in the station.

The state transition diagram of M/M/c queuing model is given in Figure A2 based on the above conditions.
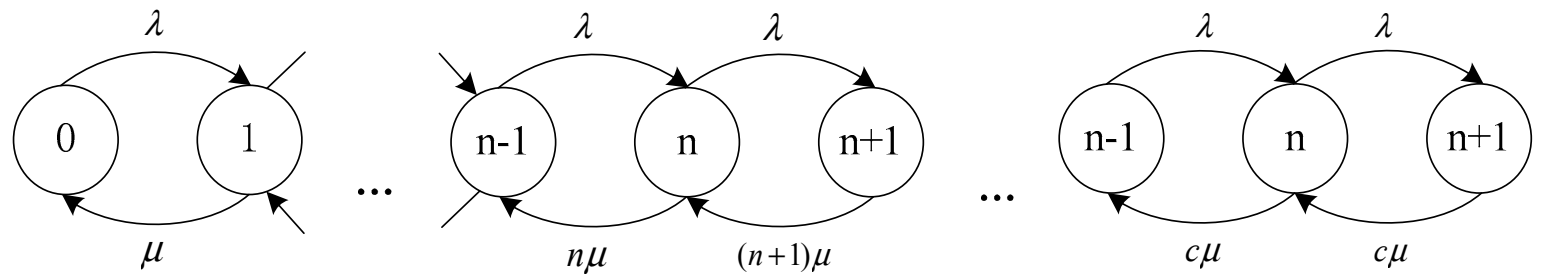

Figure A2. M/M/c queuing model state transition.

The queue length and waiting time of each EV user at charging station can be obtained as follows:

$$
\left\{\begin{array}{l}
L_{s}=L_{q}+\frac{\lambda}{\mu} \\
L_{q}=\sum_{n=c+1}^{\infty}(n-c) P_{n}=\frac{(c \rho)^{c} \rho}{c !(1-\rho)^{2}} P_{0} \\
T_{s}=\frac{L_{s}}{\lambda} \\
T_{q}=\frac{L_{q}}{\lambda}
\end{array}\right.
$$


where $L_{s}$ is the average queue length considering the entering process of new EVs to be charged, $L_{q}$ is the queue length inside the charging station, $T_{s}$ is the average residence time, $T_{q}$ is the average waiting time, which is used to calculate the total charging time $T_{d}$ in Equation (1) of the original manuscript.

\section{References}

1. Yong, J.Y.; Ramachandaramurthy, V.K.; Tan, K.M.; Mithulananthan, N. A review on the state-of-the-art technologies of electric vehicle, its impacts and prospects. Renew. Sustain. Energy Rev. 2015, 49, 365-385. [CrossRef]

2. Xiong, J.; Zhang, K.; Guo, Y.; Su, W. Investigate the impacts of PEV charging facilities on integrated electric distribution system and electrified transportation system. IEEE Trans. Transp. Electr. 2015, 1, 178-187. [CrossRef]

3. Clement-Nyns, K.; Haesen, E.; Driesen, J. The impact of charging plug-in hybrid electric vehicles on a residential distribution grid. IEEE Trans. Power Syst. 2010, 25, 371-380. [CrossRef]

4. Meyers, M.K.; Schneider, K.; Pratt, R. Impacts Assessment of Plug-in Hybrid Vehicles on Electric Utilities and Regional U.S. Power Grids Part 1: Technical Analysis; Pacific Northwest National laboratory: Richland, WA, USA, 2007.

5. Grunditz, E.; Thiringer, T. Performance analysis of current BEVs based on a comprehensive review of specifications. IEEE Trans. Transp. Electr. 2016, 2, 270-289. [CrossRef]

6. García-Villalobos, J.; Zamora, I.; San Martín, J.I.; Asensio, F.J.; Aperribay, V. Plug-in electric vehicles in electric distribution networks: A review of smart charging approaches. Renew. Sustain. Energy Rev. 2014, 38, 717-731. [CrossRef]

7. Uhlig, R.; Stötzel, M.; Zdrallek, M.; Neusel-Lange, N. Dynamic grid support with EV charging management considering user requirements. In Proceedings of the CIRED Workshop 2016, Helsinki, Finland, 14-15 June 2016; pp. $1-4$.

8. Mohsenian-Rad, A.; Leon-Garcia, A. Optimal residential load control with price prediction in real-time electricity pricing environments. IEEE Trans. Smart Grid 2010, 1, 120-133. [CrossRef]

9. Qi, W.; Xu, Z.; Shen, Z.; Hu, Z.; Song, Y. Hierarchical coordinated control of plug-in electric vehicles charging in multifamily dwellings. IEEE Trans. Smart Grid 2014, 5, 1465-1474. [CrossRef]

10. $\mathrm{Xu}, \mathrm{Z}$; $\mathrm{Hu}, \mathrm{Z}$.; Song, $\mathrm{Y}$;; Zhang, H. Coordinated charging strategy for PEV charging stations based on dynamic time-of-use tariffs. Proc. CSEE 2014, 34, 3638-3646.

11. Suman, S.; Katiyar, R.; Vijayvargiya, A.; Jain, P.; Bhakar, R. An optimally controlled charging scheme motivating EV owners for supporting grid stability. In Proceedings of the 2016 National Power Systems Conference (NPSC), Bhubaneswar, India, 19-21 December 2016; pp. 1-6.

12. Song, Y.; Zheng, Y.; Hill, D.J. Optimal Scheduling for EV charging stations in distribution networks: A convexified model. IEEE Trans. Power Syst. 2017, 32, 1574-1575. [CrossRef]

13. Deilami, S.; Masoum, A.S.; Moses, P.S.; Masoum, M.A.S. Real-time coordination of plug-in electric vehicle charging in smart grids to minimize power losses and improve voltage profile. IEEE Trans. Smart Grid 2011, 2, 456-467. [CrossRef]

14. Chen, Q.; Wang, F.; Hodge, B.M.; Zhang, J.; Li, Z.; Shafie-khah, M.; Catalao, J.P.S. Dynamic Price Vector Formation Model Based Automatic Demand Response Strategy for PV-assisted EV Charging Station. IEEE Trans. Smart Grid. 2017, 99, 1. [CrossRef]

15. Lecce, V.D.; Amato, A. Route planning and user interface for an advanced intelligent transport system. IET Intell. Transp. Syst. 2011, 5, 149-158. [CrossRef]

16. Nie, C.; Jia, S. Research on the theoretical basis and evolution of discrete choice models. Quant. Tech. Econ. 2005, 12, 151-159.

17. Luo, J.; Li, X.F.; Li, X.H. Application of mixed multinomial logit models in urban traffic split of Hefei City. In Proceedings of the 2007 International Conference on Wireless Communications, Networking and Mobile Computing, Shanghai, China, 1-25 September 2007; pp. 6464-6467.

18. Delucchi, M.A. The Annualized Social Cost of Motor-Vehicle Use in U.S., 1990-1991: Summary of Theory, Data, Methods and Results; University of California Transportation Center: Berkeley, CA, USA, 1998.

19. Lu, X.; Wang, J. OECD, Internalizing the Social Costs of Transport; Environment and Science Press of China: Beijing, China, 1996. 
20. Mackie, P.J.; Jara-Diaz, S.; Fowkes, A.S. The value of travel time savings in evaluation. Transp. Res. Part E 2001, 37, 91-106. [CrossRef]

21. Xu, T.; Lan, Z.; Hu, D.; Sun, X.; Wang, W. Influence of trip cost on trip mode for resident. J. Traffic Transp. Eng. 2013, 13, 91-97.

22. Ajjarapu, V.; Christy, C. The continuation power flow: A tool for steady state voltage stability analysis. IEEE Trans. Power Syst. 1992, 7, 416-423. [CrossRef]

23. Ramirez-Rosado, I.J.; Dominguez-Navarro, J.A. Possibilistic model based on fuzzy sets for the multiobjective optimal planning of electric power distribution networks. IEEE Trans. Power Syst. 2004, 19, 1801-1810. [CrossRef]

24. Dong, X.; Mu, Y.; Jia, H.; Wu, J.; Yu, X. Planning of fast EV charging stations on a round freeway. IEEE Trans. Sustain. Energy 2016, 7, 1452-1461. [CrossRef]

25. GB/T 12325-2008-Power Quality. Deviation of Supply Voltage. Available online: http://www.zjsis.cn/ DataCenter/Standard/StdDetail.aspx?ca=qWH2Tnwi4LE=\&Token= $\backslash$ protect $\backslash T 1 \backslash$ textdollarToken $\backslash$ protect $\backslash$ T1 \textdollar\&First=First (accessed on 18 June 2008).

26. Nielsen, J.G.; Newman, M.; Nielsen, H. Control and testing of a dynamic voltage restorer at medium voltage level. IEEE Trans. Power Electr. 2004, 19, 806-813. [CrossRef]

(C) 2017 by the authors. Licensee MDPI, Basel, Switzerland. This article is an open access article distributed under the terms and conditions of the Creative Commons Attribution (CC BY) license (http://creativecommons.org/licenses/by/4.0/). 